\title{
CUSTOS INSTITUCIONAIS DA ACUMULAÇÃO DE RESERVAS INTERNACIONAIS
}

\author{
Lucca Henrique Gustafson Rodrigues \\ Graduando do curso de Ciências Econômicas - UNB \\ E-mail: lucca1509@gmail.com
}

\section{RESUMO}

A partir de uma literatura crítica da acumulação de reservas internacionais, o presente artigo pretende analisar quais as consequências econômico-contábeis desse processo. Argumenta-se que a recente acumulação de reservas somada a uma alta volatilidade cambial impõe custos institucionais relevantes que obrigam o redesenho das relações legais entre o Tesouro Nacional e $\circ$ Banco Central. Para isso, é realizada uma análise crítica das leis 11.803/2008 e 13.820/2019 a luz dessa problemática no Brasil.

Palavras-chave: Banco Central; Reservas Internacionais; Volatilidade cambial; Tesouro Nacional.

\section{ABSTRACT}

Drawing on a critical literature of the international reserve accumulation process, the present article intends to assess the economic and accounting consequences of this process. It is argued that the recent reserves accumulation coupled with high exchange rate volatility imposes relevant institutional costs that require the redesign of the Treasury and the Central Bank legal relations. For this, a critical analysis of laws $11.803 / 2008$ and 13.820/2019 is carried out in light of this issue in Brazil.

Keywords: Central Bank; International reserves; Exchange rate volatility; Treasury. 


\section{Rodrigues}

\section{INTRODUÇÃO}

A acumulação de reservas internacionais é um fenômeno inédito na história. A realidade brasileira sempre foi marcada pela escassez de divisas e sucessivas crises de balanço de pagamentos. $O$ processo de acumulação de reservas vem para alterar esse cenário. Fruto de um novo regime de liquidez internacional, ele se tornou uma característica comum entre países com uma inserção subordinada na economia mundial, como é o caso do Brasil (PAINCEIRA, $2012)$.

Entre 2006 e 2011, o Banco Central do Brasil (BCB) multiplicou por mais de 7 vezes o volume das reservas brasileiras. Isto trouxe mudanças importantes, tanto quantitativas quanto qualitativas para o seu balanço, o que implica a necessidade de se fazer novas perguntas para compreender as consequências desse processo. Uma grande parte da literatura analisa esse fenômeno como estritamente benéfico para os países como Brasil. Ainda que não discorde dos benefícios que emergem da acumulação de reservas internacionais, este trabalho pretende construir, com base em uma literatura crítica, uma análise dos custos institucionais desse processo, em especial para a realidade brasileira.

Assim, a escolha do tema perpassa por uma motivação central, o qual também norteará o estudo subsequente, isto é: o fato de que o processo de acumulação de reservas internacionais é um fenômeno recente, intenso e com custos consideráveis. Para tanto, entender quais são as especificidades do caso brasileiro se apresenta como elemento concreto e fio condutor da discussão. Longe de esgotar a matéria ou prover uma resposta definitiva, este trabalho se questionará, em última instância qual o impacto desse processo para as contas públicas.

Frente a isso, o problema de pesquisa se desenha a partir do questionamento teórico das consequências econômico-contábeis do processo de acumulação de divisas, no âmbito institucional do setor público e do comportamento do Banco Central. A metodologia se baseia em uma análise crítica, a partir da literatura, das leis 11.803/2008 e 13.820/2019, as quais foram desenhadas primordialmente para lidar com as mudanças impostas pelo processo de acumulação de reservas.

Para tanto, na primeira seção se apresentará a literatura com a qual o artigo dialoga e baseia suas análises. Na segunda seção, se discutirá em linhas gerais a estrutura institucional que rege as relações entre o Tesouro Nacional (TN) e $\circ B C B$, em especial no que tange as reservas internacionais. Em seguida será feita uma análise das leis 11.803/2008 e 13.820/2019 nas seções 3 e 4, respectivamente. Na seção 5 é feita uma breve comparação internacional. Por fim, haverá uma conclusão, na qual será possivel perceber que a maior 
dificuldade desse processo deriva da alta volatilidade cambial do Real, que leva a existência de ganhos/perdas não realizados no balanço do $B C B$.

\section{POR QUE OS PAÍSES ACUMULAM RESERVAS?}

A primeira pergunta que esse artigo se propõe a abordar é porque o Brasil, e os países com estruturas econômicas similares, se propuseram a acumular volumes de reservas cada vez mais substanciais. De acordo com FMI (2015), para propósitos de análise de reservas internacionais, o Brasil é um país com deepening financial market. O FMI (2013) explica que, para essas economias, "reserves significantly reduce the risks of a currency crisis, as well as the number of episodes of shortage of foreign exchange market liquidity" (p. 8), ou seja, as reservas funcionam como uma profilaxia contra crises cambiais e escassez de divisas. Como esses países não são emissores de moedas conversíveis no plano internacional é necessário que eles possuam reservas em moedas conversíveis. Essa quantia de reservas normalmente é chamada de "colchão de liquidez".

Gráfico 1 - Comparação volume de reservas internacionais - em milhões US\$

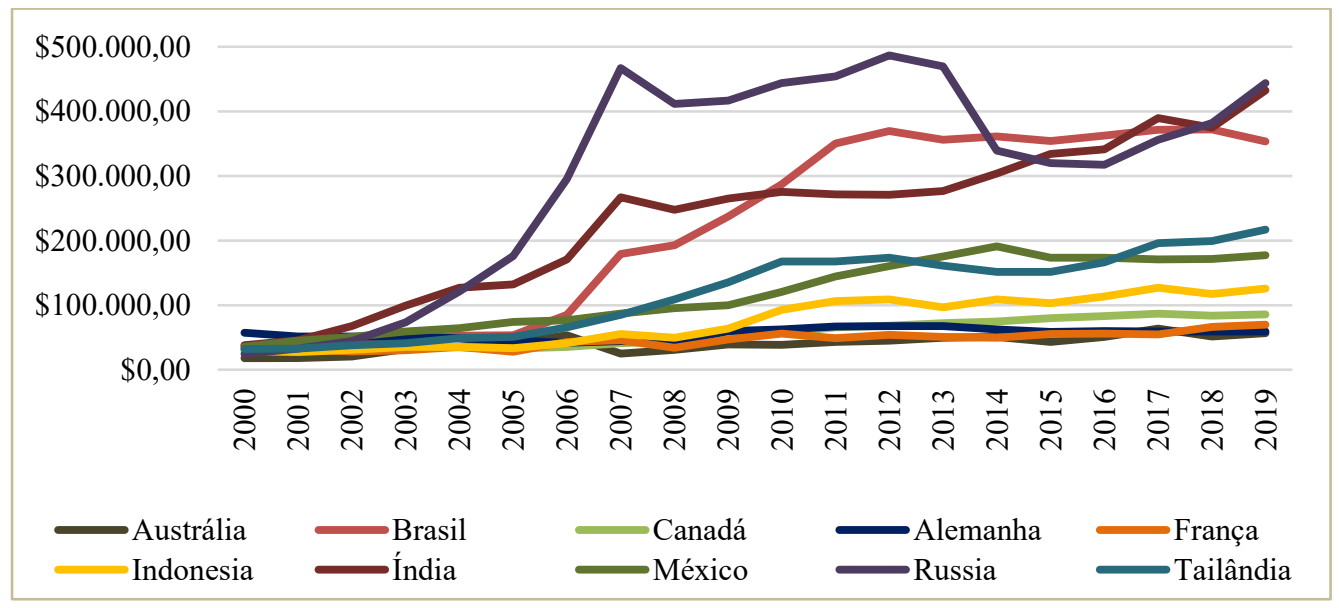

Fonte: Banco Mundial (Total reserves minus gold (current US\$)); Elaboração própria.

Carvalho (2010) explica que a demanda por essas reservas deriva da necessidade de liquidez, ou seja, de meios de pagamento no plano internacional. Além disso, a liberalização financeira que se deu no fim do século passado, houve um aumento da volatilidade e da incerteza no resultado do balanço de pagamentos. Aliado a isso, a reversão dos fluxos de capitais e os pacotes de socorro financeiro do $\mathrm{FMI}$ nos anos 90 deixou uma lembrança amarga 


\section{Rodrigues}

aos países em desenvolvimento, os quais viram na acumulação de reservas a melhor saída possível (ibid).

Prates e Andrade (2013) explicam que o sistema monetário é caracterizado por uma estrutura hierárquica entre moedas, ou seja, uma estrutura em que apenas algumas moedas são conversíveis no sistema internacional por serem utilizadas como unidade de conta dos contratos e meio de troca das transações. Essa caracterização implica uma maior vulnerabilidade externa das economias na base da hierarquia, como o Brasil e os países emergente, bem como maior volatilidade em suas taxas de câmbio, fatores os quais imputam a necessidade de se acumular esse "colchão de liquidez" em forma de reservas.

Com reservas elevadas, os países emergentes se tornam menos dependentes de fluxos temporários de capitais e ganham maior autonomia. A política de acúmulo de reservas é então uma estratégia desses países frente aos constrangimentos da estrutura internacional. Todavia, ela não pode ser vista de maneira inocente. $O$ processo de acumulação de reservas, apesar de consequências positivas, não é sem custos.

Painceira (2012) argumenta que esse processo desenvolveu uma relação abusiva entre os EUA e os países que acumularam reservas por meio de um "tributo passivo". Basicamente, o FED, ao atuar como Banco Central do mundo, aufere receita de senhoriagem pela emissão dos dólares acumulados. Dessa forma, criou-se um fluxo constante de capital dos países subdesenvolvidos aos países desenvolvidos, contrariando a lógica tradicional (ibid).

Além disso, para acumular essas reservas em seus balanços, os países emergentes tiveram que esterilizar a entrada de divisas no país para impedir seu possível efeito inflacionário, a partir da emissão de títulos públicos e pressão para cima na dívida interna (PAINCEIRA, 2012). Esse processo também intensificou a financeirização dos países emergentes e corroborou as tendências de desenvolvimento desigual entre países (KALTENBRUNNER; PAINCEIRA, 2018).

O presente artigo visa trazer um novo elemento para essa literatura ao incorporar a dimensão institucional nos custos de se acumular reservas. Utilizando o Brasil como estudo de caso, argumenta-se que a estrutura hierárquica e desigual descrita até aqui, ao causar uma elevada volatilidade cambial, imputa custos institucionais importantes para a regulação das relações entre os Tesouros e os Bancos Centrais dos países emergentes. 


\section{RELAÇÕES TESOURO E BANCO CENTRAL NO BRASIL}

O Tesouro Nacional (TN) e o Banco Central do Brasil (BCB), como principais responsáveis pela política fiscal e monetária, respectivamente, representam um tema central para a administração pública. A regulação institucional e normativa das relações entre esses dois órgãos no Brasil é extensa e remonta à Constituição Federal de 1988. Muitas mudanças ocorreram desde então na legislação que se propôs a tratar dessa matéria, porém, para os fins deste artigo, não é necessário recriar toda essa trajetória normativa. Nesse sentido, serão apontadas apenas as determinações duradouras e que tiveram impactos econômicos relevantes para as contas pública. A análise também se restringirá a investigar o resultado financeiro do $B C B$ como variável relevante para o entendimento das relações $T N$ e $B C B$.

$\mathrm{Na}$ Constituição Federal de 88, os artigos 163, 164 e 165, § $9^{\circ}$, II, já estabeleciam a necessidade de leis complementares para tratar do tema "relacionamento entre TN e BC" (CARVALHO JR, 2016). Depois disso, a lei $n^{\circ} 7.862 / 1989$ e a lei $n^{\circ} 9.069 / 1994$ (Plano Real) tocaram no assunto, porém apenas 10 anos depois que o desenho vigente hoje começou a ser estabelecido de maneira consistente. A medida provisória (MP) $n^{\circ} 1.789 / 1998$ estabeleceu os parâmetros gerais de como o resultado apurado pelo $B C B$ deveria ser operacionalizado.

No artigo $3^{\circ}$, l, ela determina que o resultado, se positivo, é obrigação do BCB para com o Tesouro e esse deve efetuar o pagamento da transferência até o décimo dia útil do exercício subsequente ao da aprovação do balanço pelo Conselho Monetário Nacional (CMN). Já no artigo $3^{\circ}$, II, afirma que, se o resultado for negativo, é obrigação da União para com o Banco Central, devendo ser realizado o pagamento também até o décimo dia útil ao do exercício subsequente.

Além disso, a MP $\mathrm{n}^{\circ} 1.789 / 1998$ determina que os valores positivos transferidos ao Tesouro devem ser destinados exclusivamente ao pagamento da dívida mobiliária federal, dando prioridade aos títulos na carteira do $B C B$. Vale ressaltar que essa determinação deixa a possibilidade de o Tesouro Nacional usar esse resultado positivo para resgatar títulos livres no mercado, o que, como será visto mais a frente, permitiu que autores criticassem a medida pois ela permitiria que a União utilizasse essas transferências para "flexibilizar" sua restrição orçamentária.

Já a lei complementar $n^{\circ} 101 / 2000$ (Lei de Responsabilidade Fiscal - LRF) mudou o texto da MP $n^{\circ} 1.789 / 1998$ no sentido de firmar que a apuração dos resultados do $B C B$ deveria ser feita semestralmente. Ademais, a LRF também alterou os prazos de transferência. Caso positivo, a transferência do $B C B$ ao TN deve ocorrer até o décimo dia útil após a aprovação do 


\section{Rodrigues}

balanço no CMN. Caso negativo, o Tesouro deve cobrir o resultado até o décimo dia útil do exercício subsequente ao da aprovação do balanço. Essa assimetria entre períodos normalmente favorece a União, a qual possui um período maior para cumprir suas obrigações frente ao $B C B$.

Vale ressaltar que os resultados financeiros do Banco Central e consequentemente o volume das transações entre o $B C B$ e o TN era, no início dos anos 2000 , de uma dimensão muito menor do que é hoje. Se observarmos a série histórica dos fluxos de resultado do $B C B$, apenas a partir de 2008 que essa cifra ganhou relevância e, principalmente, maior volatilidade. Isso se deu pela política de acúmulo de reservas internacionais promovido pelo Banco Central. Esse processo começou no meio do ciclo de commodities, período em que houve uma valorização do preço de produtos primários no mercado mundial puxada, principalmente, pela demanda chinesa. A decisão de acumulação rápida de reservas começa em 2006, após a quitação do empréstimo com o FMl ao final de 2005.

Gráfico 2 - Série história das reservas internacionais brasileiras - em milhões de US\$

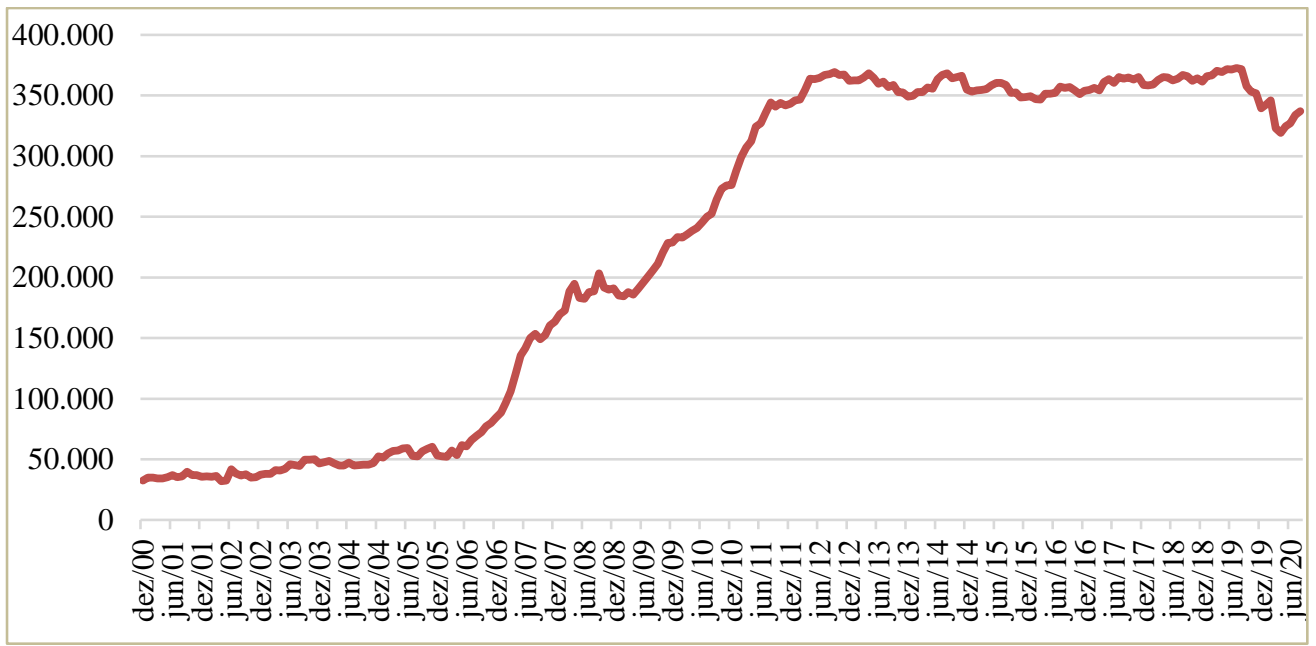

Fonte: Séries históricas (3547) - Banco Central; Elaboração própria

Brasil, como tradicional exportador de commodities, se favoreceu desse processo e acumulou sucessivos superávits comerciais que garantiram a entrada contínua de divisas no país. O resultado das transações correntes, todavia, permaneceu deficitário em grande parte do período devido a balança de rendas. Dessa forma, o que garantiu a entrada líquida de capital no país e uma posição superavitária no balanço de pagamentos foi a conta financeira. Houve 
uma grande entrada de capital no país durante esse período, tanto em forma investimento direito quanto em forma investimento de portfólio.

A partir da decomposição do fluxo de contas do balanço de pagamento nesse período, é possível ver um aumento da entrada de capital principalmente a partir de 2009. Essa onda de liquidez internacional após 2008 foi consequência das políticas de liquidez para sanar a crise que transbordaram para os países com maiores taxas de juros, como o Brasil, por meio de arbitragem. Em suma, pode-se argumentar que a segunda metade da primeira década dos anos 2000 foi marcada por uma inédita liquidez internacional, redução vulnerabilidades externas e fluxo de divisas para países subdesenvolvidos. $O$ que levou, em outras palavras, à acumulação de reservas com dinheiro emprestado.

Gráfico 3 - Decomposição fluxo de reservas - em milhões de US\$

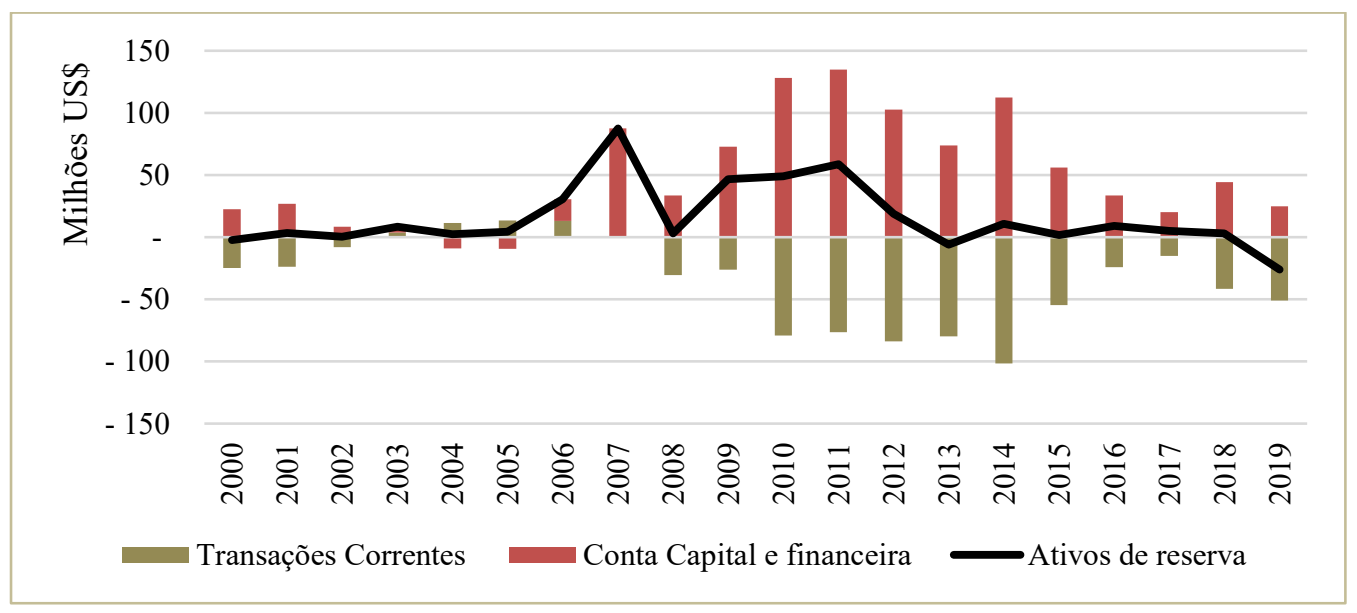

Fonte: Tabelas Especiais (BPM6) - Banco Central; Elaboração própria' ${ }^{1}$

Nesse período, $O B C B$ iniciou uma política de compras regulares de dólares no mercado primário, aumentando consideravelmente o balanço da instituição. Basicamente, a política adotada foi absorver o fluxo de câmbio pela compra de reservas (ou prover a liquidez quando mercado estiver comprado), ou seja, o aumento da entrada de divisas levou a um aumento da acumulação (in)voluntária de reservas pelo Banco Central (ROSSI, 2016). O montante de reservas saiu de cerca de US\$ 50 bilhões no começo de 2007 para mais de US\$350 bilhões

${ }^{1}$ A conta capital foi excluída pois seu valor é irrisório.

Revista Multiface | Belo Horizonte | v. 9, n. 1, p. 59-78, 2021 


\section{Rodrigues}

em 2012. As reservas internacionais fazem parte do ativo do Banco Central e, portanto, seu valor interfere no resultado financeiro da instituição. Isso porque, como todo ativo cotado livremente, as reservas internacionais têm seu valor suscetível a oscilações de mercado

$O$ dilema surge quando um desses ativos compõe a maior parte do balanço do $B C B$ e tem seu valor oscilando diariamente pela cotação do câmbio. Dessa forma, o resultado financeiro do Banco Central mudou qualitativamente e quantitativamente desde que esse processo de acúmulo de divisas começou e por isso novas legislações surgiram para lidar com a nova realidade contábil da entidade monetária.

\section{A LEI No $11.803 / 08$}

A lei $n^{\circ} 11.803 / 08$ surge exatamente no âmbito de lidar com essas mudanças que o Banco Central do Brasil vinha observando desde que o processo de acúmulo de reservas internacionais se iniciou. Na Exposição de Motivos da MP 435/08, que veio a se tornar a lei aqui em questão, já se esclarecia qual era o problema a ser resolvido:

"8. Conquanto atenda ao desiderato de tornar mais sólida a posição externa do País, a política de reforço das reservas cambiais, somada aos impactos decorrentes das intervenções da autoridade monetária no mercado interno mediante $\circ$ emprego de derivativos cambiais, tem implicado volatilidade no resultado do Banco Central do Brasil. Isso ocorre porque, em consonância com as práticas contábeis nacionais e internacionais, a lei determina que as demonstrações do Banco Central do Brasil sigam o regime de competência para o reconhecimento de receitas e despesas. Semelhante procedimento conduz a que a apuração, em moeda nacional, do estoque de reservas cambiais e derivativos cambiais detidos pelo Banco Central do Brasil sofra os efeitos das oscilações na taxa de câmbio, a despeito da possibilidade de reversão, em data futura, de receitas e despesas com variações cambiais." (MACHADO; TOMBINI, 2008).

Nesse sentido, o trecho é elucidativo pois esclarece o ponto central aqui discutido. A política de compras de divisas pelo $B C B$, como mencionado, começou a causar intensa volatilidade no valor do seu balanço patrimonial devido aos efeitos da oscilação da taxa de câmbio na cotação a mercado desses ativos. Uma vez que a contabilidade pública é realizada em regime de competência, ou seja, que contabiliza valores financeiros antes de sua realização 
contábil, a variação do valor das reservas, ainda que não vendidas em mercado, é contabilizada pelo $B C B$. Assim, quando o real deprecia frente ao dólar, por exemplo, as reservas passam a valer mais em moeda nacional e incorre um ganho financeiro para a autoridade monetária mesmo sem a venda desses ativos e sem entrada ou saída de caixa.

Antes de 2008, o resultado financeiro do Banco Central era regido pela legislação mais recente à época, a LRF. Já foram apresentados aqui os dispositivos básicos que nela apareceram, porém, vale ressaltar que as transferências de lucros e prejuízos do $B C B$ eram realizadas até então por transferências simétricas de valores monetários. Isso quer dizer que, em caso de lucro, $\circ$ BCB transferia o valor em dinheiro para o TN. Já em caso de prejuízo, o TN deveria cobrir a perda também transferindo o valor em dinheiro para ○ BCB. Assim, havia uma simetria entre a forma das transferências entre as instituições (MENDES, 2016).

Em 2008, a MP 435/08 foi convertida na lei $n^{\circ} 11.803 / 08$ e mudou o ordenamento jurídico e contábil que regia o tratamento dos resultados financeiros do $B C B$. A primeira e principal mudança está presente no artigo $6^{\circ}, 0$ qual determinava a separação do resultado do Banco Central em duas partes: resultado patrimonial e equalização cambial. $O$ resultado patrimonial passou a representar o resultado financeiro "tradicional" do BCB, ou seja, o resultado que ele obtém da diferença entre os rendimentos de seus passivos e seus ativos. Aqui vale mencionar que é esperado resultados estruturalmente positivos para $\circ B C B$, uma vez que ele emite passivos que não rendem juros (moeda) para adquirir ativos que rendem juros (títulos públicos, títulos privados, reservas internacionais, entre outros).

Já a equalização cambial passou a representar a parte do resultado financeiro do Banco Central relacionado às operações com reservas cambiais e com derivativos cambiais. Essas duas modalidades fazem parte do braço de política cambial, delegado à autoridade monetária, e se diferenciam das demais operações entre ativos e passivos no balanço do $B C B$ pela sua volatilidade ocasionada pelas variações na taxa de câmbio. Todavia, fez-se necessário ainda diferenciar essas duas operações entre si.

No caso das reservas internacionais, a remarcação de seu valor a mercado incorre num ganho puramente contábil devido ao regime de competência adotado pelo $B C B$, mas sem que haja realização desse ganho. Por outro lado, as operações com swaps cambiais implicam a troca efetiva de valores monetários. Para esclarecer, os swaps cambiais são operações em que o Banco Central se compromete a fornecer hedge cambial somado ao valor do cupom cambial em $t+1$, quando a outra ponta do contrato deve pagar a Selic para o BCB. Nesse contexto, os swaps (reversos) funcionam quando há expectativa de depreciação (apreciação) da taxa de 


\section{Rodrigues}

câmbio e o Banco Central entra vendido (comprado) no contrato para fornecer um seguro aos agentes que querem se proteger dessa variação. $O$ importante a salientar aqui é que em $t+1$ há efetiva troca financeira entre as duas pontas.

Dessa forma, embora tanto o resultado derivado da marcação a mercado das reservas e dos swaps dependam do câmbio, o primeiro refere-se a um resultado puramente contábil, enquanto o segundo deriva de um custo efetivo para $\circ$ BCB. Isso causa um sistema de compensação parcial entre os resultados realizados e não realizados dentro da conta de equalização cambial, uma vez que o efeito financeiro dos swaps e da marcação a mercado das reservas tem sentido contrário. Em outras palavras, quando há uma desvalorização (valorização) do real, o valor das reservas em reais aumenta (diminui), incorrendo um ganho (perda) para o governo. Já pela perspectiva dos swaps, a desvalorização (valorização) acarreta um custo ao $B C B$, o qual entra vendido (comprado) e deve cobrir essa variação à outra ponta do contrato. Como o valor das operações com reservas é consideravelmente maior que as com swaps, a primeira é sempre responsável por determinar o sinal da conta de equalização cambial (VIANA, $2018)$.

Em suma, o que a lei $\mathrm{n}^{\circ} 11.803 / 2008 \mathrm{fez}$ de mais fundamental foi separar o resultado obtido pelo $B C B$ em duas partes: uma que envolvesse diretamente questões cambiais e outra referente às atividades tradicionais com os demais ativos e passivos de seu balanço. A série histórica dos resultados financeiros apurados pelo Banco Central está representada pelo gráfico abaixo.

Gráfico 4 - Resultado financeiro do Banco Central - em milhares de Reais

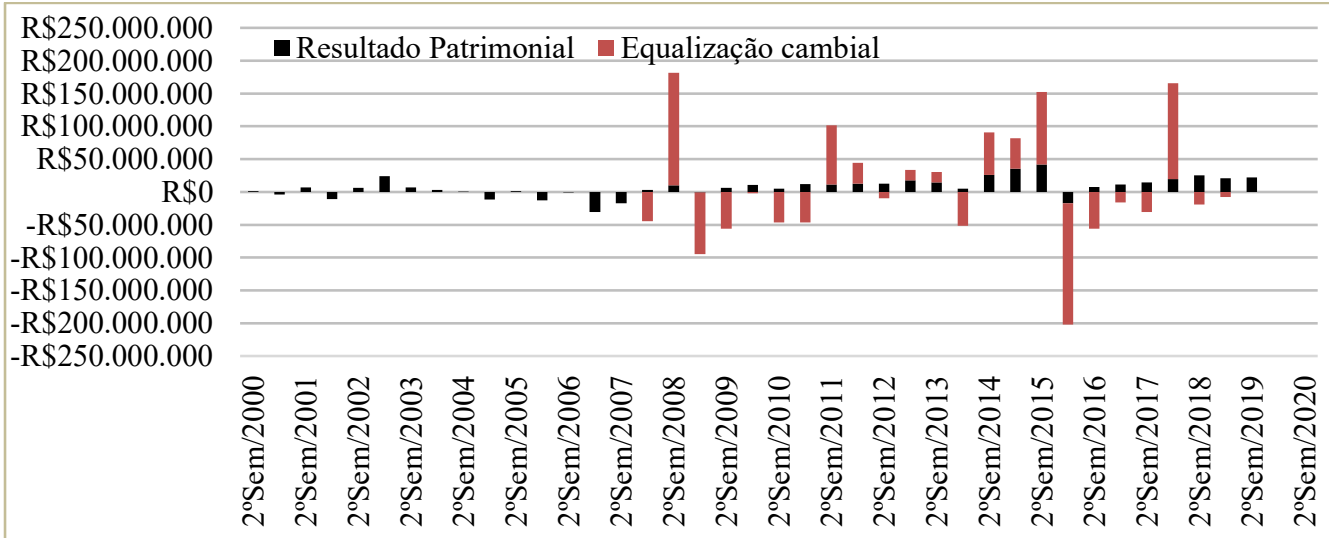

Fonte: Demonstrações Financeiras Contábeis - Banco Central; Elaboração própria 
Outra mudança importante que a lei $n^{\circ} 11.803 / 2008$ trouxe está presente no artigo $5^{\circ}$ e discorre sobre a forma que $\circ \mathrm{TN}$ deve cobrir os resultados negativos incorridos pelo $\mathrm{BCB}$. A partir dessa lei, o Tesouro Nacional não mais era obrigado a transferir o valor em dinheiro ao Banco Central e passou ser permitida a emissão de títulos da dívida para cobrir essa obrigação. Aqui vale analisar mais atenciosamente 0 argumento de simetria entre as transferências e quais são os impactos dessa mudança.

Primeiramente, observando a contabilidade do mecanismo de equalização cambial, a figura 1 sumariza bem essa nova assimetria de instrumentos. Em caso de desvalorização, o valor em real das reservas internacionais sobe e, como contrapartida, há uma transferência à Conta Única do Tesouro, que também cresce no passivo do BCB. Já no caso de valorização cambial, o valor em real das divisas cai e para manter a igualdade no balanço do Banco Central, o Tesouro transfere títulos à carteira de ativos doméstico do BCB para compensar a perda nos ativos totais.

Figura 1 - Mecanismo de ajuste dos balanços do $T N$ e do $B C B$

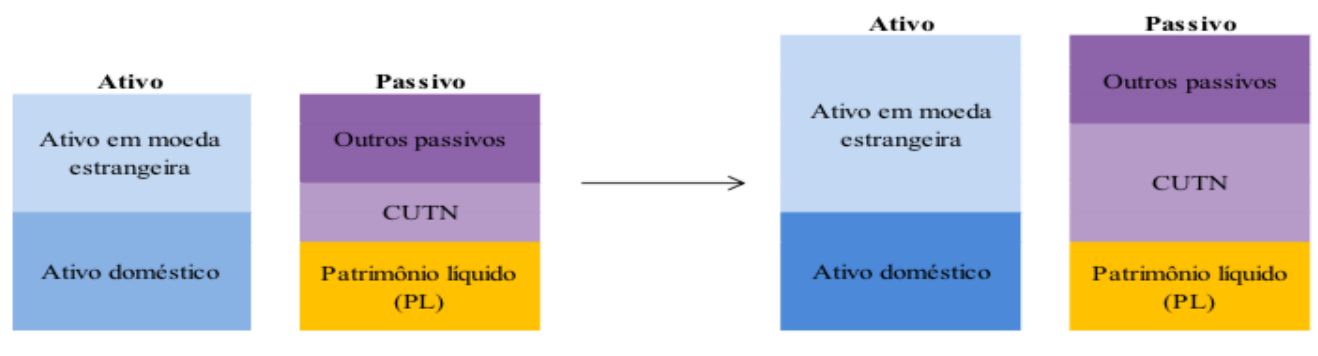

Efeito da desvalorização cambial sob mecanismo de equalização cambial

1. Desvalorização cambial provoca expansão (em reais) dos ativos em moeda estrangeira;

2. BCB compensa na totalidade o ganho com o ativo em moeda estrangeira por meio da despesa de transferêneia, em dinheiro, do resultado cambial para a CUTN.

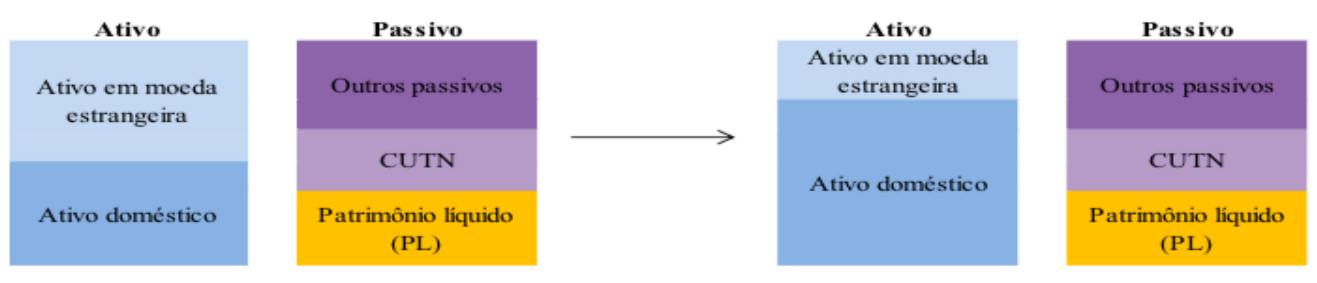

Efeito da valorização cambial sob mecanismo de equalização cambial

1. Valorização cambial provoca diminuição (em reais) dos ativos em moeda estrangeira;

2. O TN compensa na totalidade o prejuízo dos ativos em moeda estrangeira por meio da transferência de títulos públicos para a carteira de títulos do $\mathrm{BCB}$ (ativo doméstico);

3. Como o pagamento foi realizado em títulos públicos, o saldo da Conta Única (CUTN) segue no mesmo patamar.

Fonte: Viana (2018) 
Antes de 2008, os resultados, positivos ou negativos, implicavam em transferências monetárias entre as duas instituições. Depois de 2008, ○ TN não mais precisava imputar as perdas dos Banco Central diretamente na sua restrição orçamentária usando os recursos livres da Conta Única para saldar essa obrigação. Mendes (2016) discute que essa mudança, somada à possibilidade de uso dos resultados financeiros positivos do $\mathrm{BCB}$ para pagamento de dívida em posse de agentes privados, flexibilizou e mascarou a verdadeira situação fiscal do país.

Para o autor, quando o resultado é negativo, a necessidade de financiamento do $B C B$ não entra na restrição orçamentária da União. Já quando positivo, o montante transferido à Conta Única passou a ser utilizado para amortização e juros da dívida junto ao mercado, liberando recursos antes destinados a estes serviços financeiros para outros gastos primários. Nesse sentido, há uma "substituição de fontes de recursos no pagamento da dívida pública como instrumento para facilitar a expansão das despesas primárias" (MENDES, 2016, p. 226), o que - autor chama de financiamento implícito do Tesouro pelo Banco Central, prática que seria vedada pelo artigo 164 da Constituição Federal.

Todavia, é importante apontar que transferência de resultado não é financiamento direto, o que seria inconstitucional. Independente do mecanismo aqui descrito, quando o governo incorre em um déficit acima do aceitável pelo mercado, haverá expansão da dívida - seja pela emissão do TN no mercado primário ou pelo enxugamento de liquidez pelo $B C$ na realização de compromissadas. Assim, não há de fato uma flexibilização da situação fiscal pois as transferências de resultados não inibem o aumento da dívida pública como a crítica de Mendes (2016) daria a entender.

Nesse sentido, percebe-se que a discussão reside na assimetria dos instrumentos usados nas transações do resultado financeiro do $B C B$, sendo uma executada em dinheiro e a outra em títulos públicos. Todavia, é possível concluir, também, que uma vez que os resultados em dinheiro transferidos do $B C B$ ao $T N$ devem ser usados exclusivamente para o pagamento da dívida pública, seja ela de posse do Banco Central ou do mercado, o resultado no gerenciamento da dívida é o mesmo. Ou seja, embora os resultados negativos do BCB pressionem a dívida para cima, quando positivos, eles também auxiliam o seu abatimento (LEISTER; MEDEIROS, 2012 ).

A crítica, portanto, deve ser entendida no sentido de que a lei $n^{\circ} 11.803 / 2008$ criava fluxos financeiros entre $\circ \mathrm{TN}$ e $\circ \mathrm{BCB}$ extremamente voláteis e pouco previsíveis ${ }^{2}$, criando situações macroeconômicas descoordenadas. Nesse sentido, no curto prazo, transferências de

2

2 Como Toneto (2020) apresenta, o real é a moeda mais volátil entre os países emergentes.

70 Revista Multiface | Belo Horizonte | v. 9, n. 1, p. 59-78, 2021 
resultados positivos podem causar distorções nos agregados macroeconômicos, gerando excesso de liquidez no mercado, por exemplo. É importante ressaltar, entretanto, que nesse entendimento a lei $11.803 / 08$ não é por si só inadequada, haja vista que esses resultados sobre o volume da dívida se anulam do ponto de vista fiscal no médio e longo prazo quando a variação no câmbio é temporária.

Além disso há uma simetria de propósitos entre as transferências. Tanto os resultados positivos quanto os negativos não eram mantidos no balanço do $B C B$, o que não cria pressões sobre seu patrimônio, e esses resultados ao mesmo tempo que pressionavam a dívida quando negativos, a reduziam quando positivos. Por fim, quando representam ganhos financeiros genuínos para a União, deveria haver mecanismos para poderem ser utilizados.

O debate acerca do mecanismo de equalização cambial e seus impactos fiscais permeou as discussões públicas, seja de cunho acadêmico ou de cunho político, no país desde sua promulgação. Algumas propostas de mudança legislativa surgiram de tais divergências. Mendes (2016), por exemplo, propôs um modelo similar ao do Banco Central norueguês, o qual criou em seu balanço um "fundo de ajustamento" e um "fundo de transferência" para armazenar os resultados contábeis da marcação a mercado das reservas e ter um fluxo de transferências mais estáveis e previsíveis entre BCB e TN. Por outro lado, Goldfjan (2016) sugere a criação de um Fundo de Reservas Cambiais e do Conselho de Política Cambial (Copoc) para gerir essas divisas fora do balanço do $B C B$ e de maneira conjunta entre o presidente da autoridade monetária e o ministro responsável pela política fiscal ${ }^{3}$.

\section{A LEI $N^{\circ} 13.820 / 2019$}

A lei $n^{\circ} 13.820 / 2019$ veio para avançar no debate em cima da lei $n^{\circ} 11.803 / 2008$ e se tornar o novo marco legal que regulamenta as relações entre o Tesouro Nacional e o Banco Central, em especial a contabilização do resultado financeiro do BCB. A lei $n^{\circ} 13.820 / 2019$ trouxe diversos avanços para autonomia monetária, como aportes automáticos de títulos livres para a carteira do $B C B$, porém para os fins deste trabalho focar-se-á nas mudanças relacionadas com a política cambial e o resultado financeiro derivado das reservas internacionais.

Em seu terceiro artigo, a lei revela a novidade:

3 Enquanto presidente do Banco Central, Goldfjan não implementou a sua proposta, embora tenha reiterado que a gestão da política monetária e a gestão da política cambial deveriam ser mantidas separadas. No início da presidência, Goldfjan manteve a política cambial bastante frouxa, porém devido às sucessivas desvalorizações do real em 2018, a venda de swaps cresceu ainda em seu mandato. 
"Art. $3^{\circ} \mathrm{A}$ parcela do resultado positivo apurado no balanço semestral do Banco Central do Brasil que corresponder ao resultado financeiro positivo de suas operações com reservas cambiais e das operações com derivativos cambiais por ele realizadas no mercado interno, observado o limite do valor integral do resultado positivo, será destinada à constituição de reserva de resultado." (BRASIL, 2019).

A partir de então, os resultados financeiros positivos derivados das operações com reservas internacionais e com swaps cambiais, que antes estavam sob a alçada da conta de equalização cambial, não serão mais obrigações do $B C B$ frente ao Tesouro Nacional. Esse resultado deverá ser mantido no balanço do Banco Central a fim de constituir reservas e não mais será transferido à Conta Única do Tesouro. A motivação dessa mudança advém da vontade de reduzir e tornar mais previsíveis os fluxos financeiros entre a autoridade monetária e a autoridade fiscal (TESOURO NACIONAL, 2019).

Já no artigo $4^{\circ}$, a lei discorre sobre a situação contrária, quando os resultados obtidos por operações cambiais forem deficitários para o BCB. A normativa dispõe que caso o resultado apurado seja negativo, haverá reversão das reservas constituídas de acordo com o artigo anterior e, se o valor exceder o volume dessas reservas, será descontada a diferença do patrimônio institucional do BCB. Aqui cabe ressaltar que a lei também estipula um piso para o valor desse patrimônio em proporção do total de seus ativos, o qual não pode ultrapassar um mínimo de $1,5 \%$.

Esse piso serve como uma garantia para manter a contabilidade do BCB robusta e não causar danos para a autonomia da autoridade monetária, a qual, em situações de sobrevalorização, poderia ter que trabalhar com patrimônio negativo para cobrir resultados advindos unicamente da marcação a mercado das divisas. Em junho de 2020, o valor do patrimônio institucional no balanço do $B C B$ era de $3,44 \%$ do seu $\mathrm{PL}$, mais que o dobro do piso estipulado pela lei $n^{\circ} 11.820 / 2019$, e também já existem mais de 523 bilhões de reais de reservas de resultado constituídas, principalmente pelo contínuo processo de desvalorização do real frente ao dólar americano no último ano. Essa fatores indicam que a priori não há risco para a manutenção do patrimônio institucional do $B C B$ no curto prazo.

Além disso, nova lei também abre exceções para transferências dos resultados apurados positivos ao TN para pagamento da dívida mobiliária federal quando "severas restrições nas condições de liquidez afetarem de forma significativa o seu refinanciamento" 
(BRASIL, 2019). A exceção, todavia, aconteceu no primeiro ano de funcionamento da lei quando - TN, ao alegar restrições de liquidez no Conselho Monetário Nacional (CMN), recebeu R \$325 bilhões referentes ao resultado nocional das reservas. Vale ressaltar que não houve venda efetiva de reservas, mas sim uma volta ao padrão de transferências de ganhos não realizados do Banco Central ao Tesouro.

Esse marco surge como um modelo intermediário entre as propostas de Mendes (2016) e Goldfjan (2016). Agora, a constituição de reservas é realizada dentro do balanço do $B C B$, tal qual o modelo de Mendes, mas não garante mecanismos automáticos de transferência ao $\mathrm{TN}$, sendo os resultados de operações cambiais não transferidos à autoridade fiscal, como é o modelo de Goldfjan.

\section{COMPARAÇÃO INTERNACIONAL}

Primeiramente, faz-se necessário pontuar que não existem regras absolutas para como lidar com as relações entre a autoridade monetária e a autoridade fiscal. Como já dito, essas duas instituições são cruciais para o funcionamento macroeconômico de cada país e consequentemente também são em alguma medida endógenas à realidade em que estão inseridas. Por exemplo, a questão aqui discutida se faz de extrema importância para países emergentes que acumularam quantidades relevantes de reservas internacionais, como apresentado na primeira seção. Países desenvolvidos, ainda que acumulem reservas em outras moedas, essas são de volume consideravelmente menor, além de que as taxas de câmbio nessas economias tendem a apresentar um comportamento mais estável.

Dito isso, existem boas práticas e convenções que guiam os Bancos Centrais em como gerir seus balanços. Uma delas é a utilização de regime de competência para mensurar o valor dos ativos e passivos nos balanços do governo (FMI, 2007b). A marcação a mercado do valor das reservas internacionais é, portanto, parte do processo contábil padrão da administração pública. Nesse sentido, o Brasil segue as melhores práticas internacionais.

Além disso, em relação ao resultado apurado pelo $B C B$, é recomendando que essa apuração siga uma regra simétrica, ou seja, que os resultados positivos e negativos tenham um mesmo mecanismo fim. Todavia, essa não é prática comum. A transferência de resultados positivos da autoridade monetária para a autoridade fiscal, embora seguindo diferentes regras e formas distintas ao redor do mundo, pode ser considerada uma norma relativamente difundida. Em contrapartida, a cobertura de resultados negativos do Banco Central não é um ponto consensual (LEISTER; MEDEIROS, 2012). 
Para lidar com esses resultados negativos, Leister e Medeiros (2012) afirmam haver duas práticas predominantes: cobertura do resultado pela autoridade fiscal ou incorporação do resultado pelo balanço do Banco Central. A primeira, recomendada pelos autores, tem o benefício de ser uma regra simétrica, na qual a autoridade fiscal se responsabiliza pelas perdas da autoridade monetária uma vez que se beneficia dos resultados positivos. É importante ressaltar, entretanto, que essa prática tende a pressionar a dívida pública para cima e pode levar a dificuldades orçamentárias no futuro.

A segunda opção diz respeito a incorporação desses déficits financeiros no próprio balanço do Banco Central. Essa medida, ainda que não interfira em nenhuma questão macroeconômica diretamente, pode levar o patrimônio líquido da autoridade monetária ficar negativo por longos períodos de tempo. Existem diversos exemplos de tal situação entre os países latino-americanos, como Peru, Paraguai, Costa Rica, entre outros. Viana (2018) destaca que o maior perigo de tal prática é limitar a atuação e eficiência da política monetária, pela queda da confiança do mercado na estabilidade da instituição e a consequente dificuldade do $B C B$ em controlar a liquidez e a inflação. Essa dificuldade, segundo o autor, seria o efeito das expectativas de agentes que, ao não entenderem a natureza do patrimônio líquido negativo do $B C$, duvidam da capacidade de uma instituição contabilmente falida de honrar com suas metas - no nosso caso, a meta de inflação.

Ao lidar com operações cambiais, o Brasil se inseria no primeiro mecanismo no período em que a lei $n^{\circ} 11.803 / 2008$ era o referencial legal relevante. Nessa época, o Tesouro Nacional era responsável por cobrir os resultados negativos do BCB dando-o aportes de títulos públicos. A partir de 2019, com a lei $n^{\circ} 11.820 / 2019$, ○ Banco Central do Brasil passou a funcionar de acordo com o segundo mecanismo. Agora, os resultados são mantidos em forma de reservas no balanço do $B C B$ e, quando negativos, são abatidos dessa mesma conta. Entretanto, a legislação brasileira criou um mecanismo para evitar o lado negativo desse mecanismo, uma vez que estipulou um piso para o patrimônio institucional do $B C B$, garantindo que esse não se tornará negativo. Essa medida, portanto, é positiva para o avanço institucional da gestão pública nacional.

Ademais, a marcação a mercado das divisas é prática comum entre os países. Todavia, em contextos de altos volumes de reservas a intensa volatilidade cambial, essa prática gera transtornos específicos uma vez que cria ganhos não realizados no balanço da autoridade monetária. De acordo com o (FMI, 2007a), "Best practice, however, is that the central bank should not distribute gains to the government until such time as they have realized by a sale of 
underlying assets" (p. 3). A lei $n^{\circ} 11.820 / 2019$ vai nesse mesmo sentido e impede a distribuição dos ganhos puramente contábeis derivados de operações cambiais para ○ TN, impedindo que ganhos não realizados sejam utilizados pela autoridade fiscal.

Em suma, não há consenso de como lidar com essa questão, mas o Brasil parece estar caminhando para um modelo robusto e consistente. Nesse sentido, as regras brasileiras se inserem dentro do debate internacional e não destoam das melhores práticas observadas. $\bigcirc$ contexto de acúmulo de reservas traz novos desafios para a economia brasileira, os quais se intensificam pela alta volatilidade cambial. Por fim, vale mencionar que essa novidade no perfil do balanço do Banco Central não é exclusiva do Brasil e, principalmente desde 2008, houve uma mudança no papel das autoridades ao redor do mundo que demandam mais pesquisas e estudos para compreender a nova realidade macroeconômica (MENDES, 2016; STELLA, 2009).

\section{CONCLUSÃO}

A acumulação de reservas internacionais não é um processo simples e trivial como possa aparentar de primeira. Ela é uma nova realidade compartilhada entre os países emergentes que se argumentou que não ser isenta de custos. Dada sua inserção subordinada na economia internacional, a acumulação de reservas gera uma transferência líquida de recursos para fora, um aumento da dívida interna e acelera a financeirização desses países. Além disso, neste artigo, se defendeu que a existência de reservas no balanço do Banco Central impõe também a necessidade de desenvolvimento de inovações legais para mediar com essa realidade.

Do ponto de vista do setor público, a acumulação de divisas cria desafios institucionais para lidar, principalmente, com os resultados monetários não realizados que surgem da variação cambial. Esse problema tem especial importância para países com alta volatilidade cambial, como é o caso brasileiro. Caso a taxa de câmbio fosse relativamente estável frente às moedas nas quais as reservas estão denominadas, não haveria problemas de coordenação graves entre $\circ \mathrm{TN}$ e $\circ \mathrm{BCB}$.

Esses problemas surgem do fato que a marcação a mercado desses ativos influência o resultado financeiro do $B C B$, que por sua vez altera qualitativamente a natureza das transferências com o TN. Em outras palavras, é o regime de alta volatilidade cambial que impõe novos desenhos institucionais e contábeis para o Brasil, que difere dos problemas "normais" dos países desenvolvidos.

Em suma, é possível concluir que o processo de acúmulo de reservas derivou de uma reposta pragmática aos fluxos internacionais de liquidez, mas que, ao se discutir esse fenômeno 


\section{Rodrigues}

no Brasil, o elemento chave de qualquer análise é a variação cambial. Assim, uma investigação maior sobre as causas e consequências da volatilidade cambial, ligadas ao processo de acumulação de reservas, é recomendada aos estudos futuros.

\section{REFERÊNCIAS}

ANDRADE, R.; PRATES, D. Exchange rate dynamics in a peripheral monetary economy. Journal of Post Keynesian Economics, v. 35, n. 3, p. 399-416, abr. 2013. Disponível em: https://www.tandfonline.com/doi/abs/10.2753/PKE0160-

3477350304?journalCode=mpke20. Acesso em: 12 jun. 2021.

\section{BANCO CENTRAL DO BRASIL. Revisão Metodológica das Estatísticas de Meios de Pagamento.} 2018. Disponível em: https://www.bcb.gov.br/content/publicacoes/notastecnicas/NT\%2048_Dstat_Dimob_novembr o_2018.pdf. Acesso em 25 mai. 2021.

CARVALHO, F. C. The Accumulation of International Reserves as a Defense Strategy. In: GRIFFITH-JONES, S. et al. (Orgs.). Time for a Visible Hand: Lesson From the 2008 World Financial Crisis. 1. ed. Oxford: Oxford University Press, 2010. p. 269-286.

CARVALHO JR, A. BC e Tesouro: um estudo sobre a Consituição, leis complementares, leis oridnárias e mdedias provisórias. In: BACHA, E. (Org.). A crise fiscal e monetária brasileira. 1. ed. Rio de Janeiro: Editora Civilização Brasileira, 2016. p. 153-186.

FMI. How Should a Central Bank Be Treated for Tax Purposes?. 2007a. Disponível em: https://www.imf.org/external/np/leg/tlaw/2007/eng/cbtt.pdf. Acesso em: 25 mai. 2021.

- Manual on Fiscal Tranparency. 2007b. Disponível em: https://www.imf.org/external/np/pp/2007/eng/101907m.pdf. Acesso em: 25 mai. 2021.

Assessing Reserve Adequacy - Further Considerations. IMF Policy Paper. 2013. Disponível em: https://www.imf.org/external/np/pp/eng/2013/111313d.pdf. Acesso em: 12 jun. 2021. 
. Assessing Reserve Adequcy - Specific Proposals. Staff Report. 2015. Disponível em: https://www.imf.org/external/np/pp/eng/2014/121914.pdf. Acesso em 12 jun. 2021.

GOLDFAJN, I. Comitê de Política Cambial para as reservas do Banco Central: uma proposta. In: BACHA, E. (Org.). A crise fiscal e monetária brasileira. 1. ed. Rio de Janeiro: Civilizaçõa Brasielira, 2016. p. 257-369.

KALTENBRUNNER, A.; PAINCEIRA, J. P. Subordinated Financial Integration and Financialisation in Emerging Capitalist Economies: The Brazilian Experience. New Political Economy, v. 23, n. 3, p. 290-313, mai. 2018. Disponível em: https://www.tandfonline.com/doi/full/10.1080/13563467.2017.1349089?src=recsys. Acesso em: 12 jun. 2021.

LEISTER, M. D.; MEDEIROS, O. L. Relacionamento entre autoridade fiscal e autoridade monetária: a experiência internacional e o caso brasileiro. Textos para discussão Tesouro Nacional, n. 13, p. $1-38,2012$ Disponível em: https://publicacoes.tesouro.gov.br/index.php/textos/issue/view/texto13. Acesso em: 25 de mai. 2021.

MACHADO, N.; TOMBINI, A. E.M.I. no 34. 2008. Disponível em: http://www.planalto.gov.br/ccivil_03/_Ato2007-2010/2008/Exm/EMI-34-MF-BCB-Mpv435-08.htm. Acesso em 25 mai. 2021.

MENDES, M. A lei $11.803 / 08$ e a relação financeira entre Tesouro Nacional e Banco Central. In: BACHA, E. (Ed.). . A crise fiscal e monetária brasileira. 1. ed. Rio de Janeiro: Civilizaçõa Brasielira, 2016. p. 205-239.

PAINCEIRA, J. C. Developing Countries in the Era of Financialization: From Deficit-Accumulation to Reserve-Accumulation. In: LAPAVITSAS, C. (Org.). Financialization in crisis. Leiden: Brill, 2012. p. 185-216.

STELLA, P. The Federal Reserve System Balance Sheet-What Happened and Why it Matters. IMF Working Papers, v. 09, n. 120, p. 1-60, 2009. Disponível em: 


\section{Rodrigues}

https://www.imf.org/external/pubs/ft/wp/2009/wp09120.pdf. Acesso em: 25 mai 2021.

TESOURO NACIONAL. Relacionamento entre o Tesouro Nacional e o Banco Central. Relatório anual do Tesouro Nacional. 2019. Disponível em: https://sisweb.tesouro.gov.br/apex/f?p=2501:9::::9:P9_ID_PUBLICACAO:29828. Acesso em: 25 mai. 2021.

VIANA, Murilo Ferreira. A Lei $\mathbf{n}^{\circ} 11.803$ de 2008 e a relação entre o Banco Central do Brasil e - Tesouro Nacional: o caso brasileiro à luz das experiências internacionais. 2018. Dissertação (mestrado) - Universidade Estadual de Campinas, Instituto de Economia, Campinas, SP. http://repositorio.unicamp.br/ispui/bitstream/REPOSIP/333416/1/Viana_MuriloFerreira_M.p df. Acesso em: 25 mai. 2021.

Artigo submetido em maio de 2021 e aprovado em junho de 2021. 